\title{
Moving towards systems innovation
}

Steigender Wohlstand schafft mehr und andere Umweltprobleme, als er löst. Zur Lösung der mit Wirtschaftswachstum einhergehenden globalen Umweltprobleme ist ein grundlegender Systemwandel nötig. Die industrielle Produktion muss Wirtschaftswachstum weitestgehend vom Ressourcenverbrauch entkoppeln. Ausgangspunkt für eine umfassende Neuorganisation der Produktionssysteme ist Wissen, das die Grundlagen für Systeminnovationen schafft. Transitionsforschung stellt dieses Wissen als Alternative zum Status Quo bereit.

$\mathrm{U}$ Von Anna J. Wieczorek und Pier Vellinga ntil the 1960's the post war economic growth was considered a great achievement of modern societies, as it was able to assure stability and welfare. The end of 1960s, however, brought criticisms of economic growth for what was seen as its darker side. The 1972 Report to the Club of Rome was a warning to the world about fatal effects of continuous exponential economic growth and its consequences: increasing pollution, overexploitation of renewable resources, exhaustion of non-renewable resources. A heated debate over economic growth and the environment was started between the supporters, who considered economic growth good for the environment and the antagonists, according to whom economic growth was the root cause of the environmental degradation and for that reason should be reduced or even reversed. As a result, in the late 1980s theoretical investigation of the relationship between economic growth and environment was started, many computer models and future forecasting were developed, but the debate could not be put to rest due to a lack of environmental data as well as differing opinions and values about what is a sustainable future. The first empirical studies were carried out only in 1990 and they revealed the existence of an inverted $\mathrm{U}$ curve relating use of energy and materials with income, the so-called Environmental Kuznets Curve (EKC). The curve was consistent with the observation that in some of the developed countries environmental pressure has been reduced while economic growth has continued. In 1992 the World Bank published a report suggesting the possibility of delinking economic growth from its environmental burden (1).

\section{Early successes}

Since the first environmental movements of the 1960s the OECD countries have been successful in using regulatory instruments to reduce pollution and overexploitation of natural resources. Technology advances made it possible to increase life expectancy, improve resource use, reduce pollution and better understand how life support systems operate at a global level. All OECD countries have developed a portfolio of environmental policies and many socio-economic imbalances have been addressed especially in more environmentally aware countries. The report by Azar on the past trends and prospects for the future decoupling indicates that there has been some decoupling of some emissions in some developed countries (2). Part of the explanation being the shift of some industries from developed to developing countries. However, according to Johnson ,...despite all the elegant rhetoric that surrounds discussions about sustainable development, we are far from heaving made significant progress toward that goal" (3). One would wonder why.

\section{Complex global environmental problems}

When we take a closer look at the Environmental Kuznets Curve as presented by the World Bank we discover that indeed it is true but only for local environmental problems such as air contamination or water pollution in the cities. The empirical evidence confirms that indeed growing income levels can be combined with improvement of local environmental quality.

This is probably for two reasons: firstly, because people take action based on health impact observations and secondly: because costs and benefits play out at the same (local/national) level and within one generation. When we talk about environmental problems that are manifest at a regional level, such as acidification and water quantity/ quality issues at the scale of river catchments, there is less evidence that people successfully address these problems as income levels go up. One reason is that upstream and upwind industrial and agricultural activities benefit from the ability to pollute and overuse environmental resources such as water and air, while downstream and downwind, people and nations experience the negative impacts. Another reason for continued environmental degradation as income levels go up, is the time delay between the act of polluting and the effect of pollution downstream.

Similar curves drawn for global environmental problems such as climate change and loss of species and habitats do not resemble Environmental Kuznets Curves at all. Empirical data illustrate that there is no income related levelling off point when we look at the relation between income and emissions of greenhouse gasses (given the predominant use of fossil fuels). The OECD list of red lights (problems that have worsened in the past, or are expected to do so in the future), next to the greenhouse gas emissions, also includes: decline in tropical forest coverage, overfishing and loss of biodiversity.

Environmental problems at this level are challenging because income levels correlate with energy use and present day energy use is coupled with carbon dioxide emissions. Similarly, the space and resources we use for our activities (housing, transport, food and also recreation) grows linearly with income projections going up; this is at the expense of natural habitats. There is also no direct correlation with human health impacts so the sense of urgency to address these issues is generally low. Finally those who could take first actions - the developed and richer countries are the least vulnerable to the effects of global environmental change and they do not feel immediate urgency to take any action. Indeed, a critical feature of global environmental change is the time scale of biophysical response: climate responds to changes in the concentration of greenhouse gases at a time scale in the order of decades to centuries and more.

Global environmental change is thus so very difficult to approach in the traditional way in which environmental problems have been addressed so far because the activities that cause these problems (energy use, food production, mobility) are deeply embedded in our cultures. The global environmental problems often originate from different sources, are characterised by a great number of stakeholders and their interests and are marked by large uncertainties. They are also urgent and require action before the effects actually become visible. 


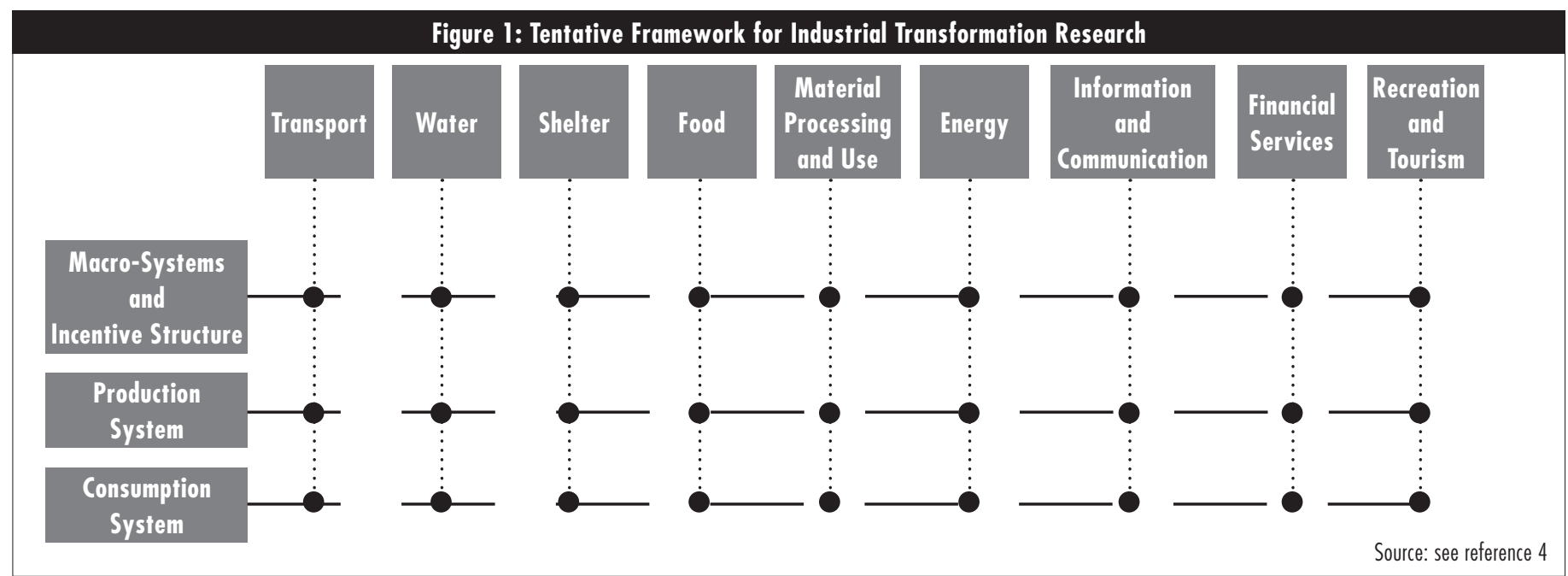

\section{Transformation - a panaceum?}

Global environmental change will test, in an unprecedented way, the capacity of the human species to manage their activities in a pro-active manner, especially when we want to combine growing income levels with a significant reduction in the impact of human activities on global life support systems. Such an approach will have to focus on systems and systems change. A system being defined as a chain of production, distribution, consumption and disposal activities including the incentives that shape the system (i.e. property, liability and fiscal laws and regulations). Given the complexity of such chains and given the need for a pro-active approach such system changes will require the involvement of society as a whole and they will require an inspiring vision to mobilize all participants. It is clear that such visions are likely to compete with one another, which can slow down the change, but this is not necessarily counter productive as competition is a driving force in itself. Furthermore, a change to more sustainable systems is only partially a matter of technology. Economic, socio-cultural and institutional change plays an equally important role. In fact, transformation can only be successful when the technological change is inherently coupled with a societal change.

These considerations and a wide international, multidisciplinary consultation provided foundations for the creation of the Industrial Transformation project (IT) of the International Human Dimensions Programme on Global Environmental Change (IHDP). The overarching goal of the IT research is threefold:

- To understand complex society-environment interactions;
- To identify driving forces for change;

- To explore development trajectories that have significantly smaller burden on the environment. The IHDP-IT programme is based on the assumption that important changes in production and consumption systems will be required in order to meet the needs and aspirations of a growing world population while using environmental resources in a sustainable manner. This type of research has to be of a multi-disciplinary character. Industrial Transformation therefore builds on the foundations of a range of social science disciplines including economics, sociology, psychology, human ecology, anthropology, political science, geography and history, as well as on the foundations of natural sciences such as physics, chemistry, biology and technological sciences. To provide a framework for the cooperation required between various disciplines, a matrix was developed (figure 1).

The rows reflect the disciplinary research fields that each has a certain tradition, while the columns describe a set of human activities aimed at meeting specific human needs (4). Through this multi-disciplinary approach, the Industrial Transformation Project strives to build on existing pillars of research and draw from expert communities while developing new research topics and radical approaches.

\section{Why Industrial Transformation?}

The word Industrial in the name of the project was selected to describe and indicate the need for a transformation of ALL human activities defined as a chain of interrelated economic activities aimed at providing a specific need for a society. Industrial Transformation was defined analogously to Industrial Metabolism and hence refers to all processes reflecting economic activity instead of those of the industrial sector alone. Industrial Transformation could also be called Societal Transformation but this word is confusing as it emphasizes changing norms, values and attitudes instead of transforming inputs into outputs. Looking at the history of how societies moved from agricultural to an industrial mode of subsistence, one could argue that many countries are past the industrialization process and therefore Industrial Transformation is over, but this is not what IT refers to. Current societies including the socalled post-industrial world are strongly based on the production of goods and services in ways that have a massive effect on environment (e.g. the energy and food sector as well as tourism and the health care sector). Industrial Transformation is therefore about transforming production and consumption based societies towards sustainability.

The road towards sustainability through the decoupling of economic development from its environmental burden proves to pose many challenges. There are many areas of human needs that need to be addressed such as food, fresh water, health, shelter, mobility and energy, to name only a few. There are also many dimensions in which sustainability needs to be achieved, including e.g., technical, socio-economic, cultural or spatial aspects. Achieving sustainability in the broad sense therefore appears to require a multitude of changes that have been referred to by analysts from different disciplinary backgrounds using a variety of concepts. System innovation, regime transformation, industrial transformation, technological transition, socioeconomic paradigm shift are some of the best known.

\section{Geographical differences}


When studying historical transformations with the aim to fuel the policy process and envisage pathways towards sustainability, it is of utmost importance to take account of regional differences within the framework of global interconnectedness. This is not only due to various levels of economic development, but also because of different climatic conditions and topography and often very different cultural and socio-political patterns. For example, the challenge for the OECD countries is to continue economic development while reducing environmental burden (de-coupling of economic growth from its environmental burden). For the South Asian region a single challenge cannot be defined since differences among and within the countries in terms of production and consumption are too large to allow for such a simplification. The rapid change to natural gas busses in New Delhi or growth of kilowatts produced by decentralized renewable energy systems in India could serve as good examples of change for many OECD countries. But at the same time, the South Asian region is home to the largest number of poor and nearly half of the two billion people without access to energy.

With repart to future and actual urban-industrial growth, the challenge for this region is to shift to patterns of economic development that are significantly less energy, resource and pollution intensive (5).

\section{- Conclusions}

Global environmental change problems such as climate change, the loss of biodiversity and the overexploitation of water resources require major changes of the way energy, food, transport and water needs are met. In view of these global environmental problems and their irreversibility, there is an urgent need to explore development trajectories and implement strategies that have a significantly smaller burden on the global environment.

The activities causing global environmental change such as the production and consumption of (fossil fuels) energy, transport, food and water are deeply embedded in our societies. Therefore traditional command-and-control policy measures will not suffice in bringing about the required changes. System innovation offers a more promising approach. It advocates a reconsideration and innovation of the entire chain of production and consumption as well as the institutional and political structures that shape relations between the two.

The international community has developed a number of research concepts and tools to address the enormous challenge of global environmental change. There is a consensus that effective research approaches should include the analyses of technological, socio-economic and institutional change. Such multidisciplinary approaches are generally presented under the name of industrial transformation research.

Industrial Transformation research as described and promoted by the International Human Dimensions Programme brings the various research approaches together (6). This programme plays an important role in the generation and sharing of the knowledge required to initiate and guide international, regional, national and local efforts towards more sustainable production and consumption processes. The character of the most urgent global environmental problems legitimises the focus on the transformation of production and consumption of energy, transport, food and water and the technical, institutional and societal elements that shape these systems.

\section{References}

(1) De Bruijn, S.M.: Economic growth and the environment. An empirical analysis. Timbergen Institute Research Series, №. 216, 1999 .

(2) Azar, C./ Holmberg, J./ Karlsson, S.: Decoupling past trends and prospects for the future. Paper commissioned by the Swedish Environmental Advisory Council,

Stockholm 2002.

(3) Johnson, D. J.: Can OECD Countries put Theory into Practice? A Blueprint for Progress Toward Sustainable Development. In: Canadian Journal of Policy Research. Volume

3, №. 22002.

(4) Vellinga, P. (ed): Research Approaches to Support the Industrial Transformation Science Plan. IHDP IT Report No.

19, Amsterdam 1999.

(5) Angel, D.P./ Rock, M.T. (eds.): Asia's clean revolution: industry, growth, and environment. Sheffield 2000.

(6) For more information see: www.uni-bonn.de/IHDP and www.vu.nl/ivm/research/ihdp-it

\section{Die AutorInnen}

Anna Wieczorek leitet die Geschäftsstelle des International Human Dimensions Programme on Global Environmental Change (IHDP IT) Projekts. Pier Vellinga ist Vorstand des IHDP IT Projekts.

Kontakt: IHDP IT Project, c/o Institute for Environmental Studies (IVM), De Boelelaan 1087, 1081 HV Amsterdam, Niederlande. E-Mail: anna.j.wieczorek@ivm.vu.nl

\section{Unternehmen und Umwelt}

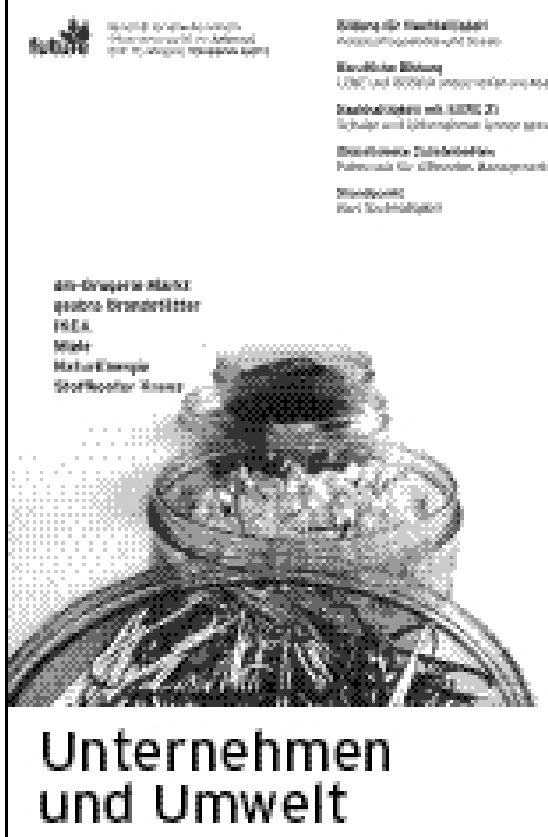

... ist die Zeitsxhrift für umweltorientierte Unternetmerapolitik von future e.V.

.. bietet Fachinformationen zum Unweltschutz und Best-Practice-Beipiek aus Unternebmen.

\section{... bietet viermal im Jahr Untemehrmers- beipiek, Literatur- und Verarataltungs- himweise.}

Mit einem Sctwerpunktthema in jedem Heft. Zum Beispiel:

1/04: Biddeng fiv Nachhaltige Entwioklung 4/03: Kampetenz nactibaltig entwickeln 3/03: Nactihaltigkert und Region 2/03: Kapital fïr Nachthaltighert 1/03: Energieeffizienz

3-4/02: Benctwanting for Sustainability 2102: Ohomarketing

1102: Nachinaltigkeit und Gewerbebus 4/01: Nachfalitigkeit in Handwerk 3101: Klimaschutz

Bestellen Sie ihr kostenloses Probe-Abo im Internet unter ww w. future-ev.de

future e.V. Büro Bochum

Arn Varenholt 123

44797 Bochum

Fon: 0234/9799513

Fax: 0234/9799514

bochumfluture-ev.de

wwow. futureev.de 
(c) 20I0 Authors; licensee IÖW and oekom verlag. This is an article distributed under the terms of the Creative Commons Attribution Non-Commercial No Derivates License (http://creativecommons.org/licenses/by-nc-nd/3.o/), which permits unrestricted use, distribution, and reproduction in any medium, provided the original work is properly cited. 